\title{
Treating substance abuse is not enough: comorbidities in consecutively admitted female prisoners
}

Jan Mir ${ }^{1}$, Sinja Kastner ${ }^{1}$, Stefan Priebe ${ }^{2}$, Norbert Konrad ${ }^{3}$, Andreas Ströhle ${ }^{1}$, Adrian P. Mundt ${ }^{2,4}$

${ }^{1}$ Department of Psychiatry and Psychotherapy, Charité Campus Mitte, Universitätsmedizin Berlin, Germany

${ }^{2}$ Unit for Social and Community Psychiatry (WHO Collaborating Centre for Mental Health Services Development), Queen Mary University of London, UK

${ }^{3}$ Institute of Forensic Psychiatry, Charité Universitätsmedizin Berlin, Germany

${ }^{4}$ Escuela de Medicina sede Puerto Montt, Universidad San Sebastián, Chile

Corresponding author:

Dr. Adrian P. Mundt

Unit for Social and Community Psychiatry

WHO Collaborating Centre for Mental Health Services Development

Queen Mary University of London

Newham Centre for Mental Health

London E13 8SP, UK

Tel: +447477085542

Email: a.mundt@qmul.ac.uk

Word count: 2275

Running title: Comorbidities in female prisoners

Manuscript pages: 21; Figure: 1; Tables: 2 


\section{Abstract}

Introduction: Several studies have pointed to high rates of substance use disorders among female prisoners. The present study aimed to assess comorbidities of substance use disorders with other mental disorders in female prisoners at admission to the penal justice system. Methods: A sample of 150 female prisoners, consecutively admitted to the penal justice system in Berlin, Germany, were interviewed using the Mini International Neuropsychiatric Interview (MINI). The presence of borderline personality disorder was assessed using the Structured Clinical Interview II for DSM-IV. Prevalence rates and comorbidities were calculated as percentage values and $95 \%$ confidence intervals $\mathrm{CI}$.

Results: Ninety-three prisoners (62\%; 95\% CI: 54-70) had substance use disorders; $n=49$ (33\%; 95\% CI: 24-42) had alcohol abuse/dependence; $n=76$ (51\%; 95\% CI: 43-59) had illicit drug abuse/dependence; $n=53$ (35\%; 95\% CI: 28-44) had opiate use disorders. In the group of inmates with substance use disorders, $84(90 \%)$ had at least one other mental disorder; $n=63$ $(68 \%)$ had comorbid affective disorders, $n=45(49 \%)$ borderline or antisocial personality disorders and $n=41(44 \%)$ comorbid anxiety disorders.

Conclusions: Female prisoners with addiction have high rates of comorbid mental disorders at admission to the penal justice system, ranging from affective to personality and anxiety disorders. Generic and robust interventions that can address different comorbid mental health problems in a flexible manner may be required to tackle wide spread addiction and improve mental health of female prisoners.

Keywords: substance use disorders, comorbidity, mental disorders, female prison population, prevalence rates, admission study 


\section{Highlights}

- A majority of $62 \%$ of females have substance use disorders at admission to prison

- Opiates are the most frequent substances of addiction in $35 \%$ of this population

- Addictions are highly comorbid with affective, personality and anxiety disorders

- Comorbidities do not differ between subgroups addicted to different substances

- Interventions should be generic, robust and flexible to cover different disorders 


\section{Introduction}

The number of imprisoned women has been increasing faster than the number of male prisoners worldwide and it has been suggested that female prisoners may have specific health care needs [1,2]. Despite this, most of the research so far has been conducted in male prisoners [3]. Existing evidence suggests that female prisoners have comparatively higher rates of addiction than male prisoners [4-8]. However, prevalence estimates for female prisoners have only been reported from few countries so far [9]. Moreover, they showed important variations between 10-24\% for alcohol abuse/dependence and 30-60\% for drug abuse/dependence for the one-year prevalence rates in a previous review [9]. The variations may be due to cultural and legal contexts. Drug abuse/dependence in consecutively admitted female prisoners might have been increasing over time. Different studies from the US reported lifetime prevalence rates of $26 \%$ in 1988 [10] and 44\% in 1996 [3]. More recent research from Australia showed that $62 \%$ of female prisoners had used illegal drugs in the six months prior to arrest without specifying whether criteria for abuse or dependence were fulfilled [11]. A study of newly committed female prisoners conducted in Ireland had reported $48 \%$ prevalence of drug use disorders [12]. Heroine had been identified as the most frequent substance causing dependence in female prisoners in the UK [13,14]. However, the types of illegal drugs of addiction were frequently not further specified in previous research. In all, the prevalence rates of drug associated disorders in female prisoners were estimated to be 13 times higher than in the general population [9].

Addiction frequently co-occurs with other mental disorders in the general population $[15,16]$. The description of such comorbidities for prison populations had been identified as research necessity in a recent meta-analysis [17]. The priority is then to develop adequate treatments, which acknowledge the primary substance of addiction and comorbidities with other mental disorders, the so called 'dual disorders' [18]. Previous research has demonstrated, with respect to nicotine addiction of prisoners, that treatment was superior to mere forced 
abstinence in smoke free jails, which by itself had hardly any affect on the addiction after release [19]. Most previous prison mental health studies have been conducted with samples from all existing prisoners with varying times spent in imprisonment. Research should assess addiction and comorbidities in newly received prisoners using structured clinical interviews to assess states of addiction prior to admission. At a later stage of imprisonment, reduced access to substances inside the penal justice systems may lead to negative scores on the standardized interview schedules resulting in missed diagnoses. Studies sampling from newly received prisoners will include mainly people with short-term and repeat sentences among them people with addiction. In contrast, studies of all existing inmates tend to include a larger proportion of long-term prisoners, for many of whom the addiction may not be the most relevant problem.

Previous prison mental health studies from Germany recruited already existing prisoners at varying stages of imprisonment and they included all male or mixed gender samples with relatively small numbers of females [20,21]. The severity of traumatic experiences was significantly related with the prevalence of substance use disorders in a study from Germany [22]. The present study conducted in Berlin, Germany, aimed to assess the prevalence rates of substance use disorders and their comorbidities with other mental disorders in female prisoners newly committed to the penal justice system. 


\section{Methods}

This was a cross-sectional study of a sample of consecutively admitted female prisoners in Berlin, Germany.

\section{Sample}

The sample was recruited from the central prison admission facility for females, which serves the state of Berlin, Germany, an urban area with 3.5 million people, including the open, semiopen and the closed systems. The facility does not serve women regarded to have reduced legal responsibility due to mental disorders in terms of $\S 20$ or $\S 21$ of the German Criminal Law. We aimed to recruit a total sample of 150 participants. The sample size was expected to yield percentage estimates with reasonable $95 \%$ confidence intervals (CI) for the total sample, i. e. $10 \%(95 \%$ CI: $5-15)$ or $20 \%(95 \%$ CI: $14-26)$. Prisoners with all types of verdict such as people in detention, remand prisoners and convicted prisoners were included in the study. The interview was usually scheduled within a week after imprisonment and always within the first month of imprisonment. Exclusion criteria for the study were the inability to communicate in German and a lack of capacity to provide informed consent.

\section{Measures}

Age, marital and employment status, educational and income level, were assessed on structured questions. The variables were dichotomized as living alone or with partner, education as low (comprising the categories 0-2 of the International Standard Classification of Education [ISCED] with all levels of education up to lower secondary levels of education) and high educational level (comprising the categories 3-6 of the ISCED with all educational levels from upper secondary level and higher [23]). Employment status was dichotomized to 
employed (including people in training under the age of 28 years) and unemployed (including people in training of 28 years or older and retired people). This classification is in accordance with German legislation which requires the long term unemployed to take part in trainings to continuously qualify for social benefits [24]. The income level was dichotomized to $€<990$ and $€ \geq 990$ per month, which was the line of relative poverty for a single person household in 2010 (http://www.diw.de/de/diw_01.c.411565.de/presse/diw_glossar/armut.html). The background of migration was assessed using an instrument developed by Schenk et al. [25]. The type of criminal offense was recorded.

\section{Mini International Neuropsychiatric Interview}

The fully structured Mini International Neuropsychiatric Interview (MINI) 6.0 [German version] was conducted to assess mental health and substance use disorders. The MINI was developed by Sheehan and Lecrubier [26] to categorize mental disorders according to the fourth version of the Diagnostic and Statistical Manual of Mental Disorders (DSM-IV). The concordance between the MINI and longer interview schedules such as the Structured Clinical Interview for DSM-IV (SCID) is characterized by good or very good kappa values for most diagnoses [27]. The inter-rater reliability of the MINI is characterized by kappa coefficients above 0.75 for all diagnoses and 0.9 for the majority of the diagnoses [27]. The test-retest reliability introducing a second clinician for the rating was very good with kappa values above 0.75 for most diagnoses and below 0.40 for only one diagnosis (current mania) [27].

\section{Structured Clinical Interview for DSM-IV}

The MINI covers the antisocial personality disorders as only axis II diagnosis. Therefore, the interview schedule was supplemented by the module for borderline personality disorder (BPD) of the SCID [28]. The inter-rater reliability of the borderline module in the SCID-II was shown to have a kappa value of 0.78 [29]. The 1-3 week test-retest reliability of the 
borderline module was shown to have a kappa value of 0.48 [30].

Fagerström Test of Nicotine Dependence

Current smoking and the degree of nicotine dependence was assessed using the Fagerström Test of Nicotine Dependence FTND [31]. Reliability estimates for the FTND were 0.56 [32]. The FTND was shown to be a valid self-report measure among alcohol- and drug dependent individuals [33]. Scores of FTND $\geq 6$ were considered high degrees of nicotine dependence.

\section{Procedure}

The capacity to give informed consent was tested by assessing the potential participant's ability to understand the purpose of the study. The field team consisted of two clinical psychologists trained and supervised by a senior consultant psychiatrist in using the instruments. The interviews lasted for 45-60 minutes and were held in a separate room of the prison to ensure confidentiality. The data were collected between April 2012 and May 2013. All interviewees provided written informed consent. The study was approved by the Ethics Board of the Charité Universitätsmedizin Berlin (EA1/302/11) and by the legal justice department of the State of Berlin, Germany (reference AL, 20.01.2012).

\section{Analyses}

Socio-demographic characteristics and prevalence rates of mental disorders were calculated as per cent values. For the prevalence rates, 95\% Confidence Intervals (CI) using a bootstrap algorithm were computed. The mean and the standard deviation of the mean (SD) were calculated for the age. The statistical analyses were made using SPSS version 20.0. 


\section{Results}

\section{Recruitment}

Figure 1 shows the flow of recruitment for the study. During the recruitment period, 338 women entered the central facility for the admission of female prisoners to the penal justice system in Berlin. Of those, 278 women were screened for recruitment, 198 fulfilled the inclusion criteria and 150 agreed to participate in the survey.

Place Figure 1 about here

\section{Socio-demographic characteristics of the sample}

The sample had a mean age of $34.3 \pm 10.8$ years. Most of the female prisoners, $n=139(93 \%)$, were living alone; $\mathrm{n}=89$ (59\%) had low educational levels corresponding to ISCED 0-2; $\mathrm{n}=113(75 \%)$ were unemployed; $\mathrm{n}=114(76 \%)$ were living below the poverty line; $\mathrm{n}=124$ (83\%) were non-migrants and 104 prisoners (69\%) were mothers of children. The index crimes were sorted to the following offense categories: $n=69$ (46\%) failure to pay a fine; $n=35$ $(23 \%)$ theft or fraud; $\mathrm{n}=16(11 \%)$ remand prisoners under investigation; $\mathrm{n}=10(7 \%)$ crimes related to drugs (possession or dealing); $\mathrm{n}=6(4 \%)$ crimes related to immigration.

Mental disorders in female prisoners with substance use disorders, with alcohol use disorders, with illicit drug use disorders and with opiate addiction Prevalence rates of mental and substance use disorders are shown in Table 1. Most prisoners, $\mathrm{n}=139,(91 \%$; 95\% CI: 85-95) had at least one mental disorder; $\mathrm{n}=97$ (65\%; 95\% CI: 57-72) had at least one affective disorder; $\mathrm{n}=93$ (62\%; 95\% CI: 54-70) had any one-year prevalence of substance use disorders without nicotine; $n=31,(21 \% ; 95 \%$ CI: $15-27)$ had alcohol 
dependence and $n=71$ (47\%; 95\% CI: 39-55) illicit drug dependence. The most important illicit substances of addiction were opiates, marihuana, cocaine and amphetamines (see Table 1). Anxiety disorders were prevalent in 65 prisoners (43\%; 95\% CI: 36-51); APD was prevalent in 41 prisoners $(27 \%$; $95 \%$ CI: $20-35)$ and BPD in 22 prisoners $(15 \%$; $95 \%$ CI: 921). Low risk of suicide was present in $n=63(42 \% ; 95 \%$ CI: $34-51)$, medium risk in $n=5(3 \%$; 95\% CI: $1-6)$ and high risk in $n=12(8 \%$; 95\% CI: 4-13) of the sample. 
Table 1: Prevalence rates of mental and substance use disorders in female prisoners

\begin{tabular}{|c|c|c|c|}
\hline \multirow[b]{2}{*}{ Mental disorder } & \multicolumn{3}{|c|}{ Total sample, $\mathbf{N}=150$} \\
\hline & $\mathbf{N}$ & $\%$ & $95 \% \mathrm{CI}$ \\
\hline$\geq 1$ disorder & 136 & 91 & 85-95 \\
\hline$\geq 2$ disorder & 107 & 71 & 64-78 \\
\hline Lifetime affective disorders & 97 & 65 & $57-72$ \\
\hline Major depression & 8 & 5 & $2-9$ \\
\hline Recurrent major depression & 12 & 8 & $4-13$ \\
\hline Previous Major Depression & 20 & 13 & $8-19$ \\
\hline Previous recurrent major depression & 20 & 13 & 8-19 \\
\hline Mania & 0 & & \\
\hline Previous mania & 3 & 2 & $0-5$ \\
\hline Bipolar I disorder & 13 & 8 & $5-13$ \\
\hline Previous bipolar I disorder & 13 & 8 & $5-13$ \\
\hline Bipolar II disorder & 2 & 1 & $0-3$ \\
\hline Previous bipolar II disorder & 6 & 4 & $1-7$ \\
\hline Current affective disorder with psychotic features & 1 & 1 & $0-2$ \\
\hline $\begin{array}{l}\text { Lifetime affective disorders with psychotic } \\
\text { symptoms }\end{array}$ & 8 & 5 & $2-9$ \\
\hline Substance use disorders without nicotine* & 93 & 62 & 54-70 \\
\hline Alcohol abuse/dependence & 49 & 33 & $25-41$ \\
\hline Alcohol abuse & 18 & 12 & $7-17$ \\
\hline Alcohol dependence & 31 & 21 & $15-27$ \\
\hline Illicit drug abuse/dependence & 76 & 51 & 43-59 \\
\hline Illicit drug abuse & 5 & 3 & $1-7$ \\
\hline Illicit drug dependence & 71 & 47 & $39-55$ \\
\hline - Opiates & 53 & 35 & $28-44$ \\
\hline$\circ$ Heroine & 41 & 27 & $20-35$ \\
\hline$\circ$ Opiate substitution & 19 & 13 & $8-20$ \\
\hline - Marihuana & 28 & 19 & $13-26$ \\
\hline - Cocaine & 25 & 17 & $11-23$ \\
\hline - Amphetamines & 14 & 9 & $5-15$ \\
\hline - Hallucinogenics & 3 & 2 & $0-4$ \\
\hline - Gamma-Hydroxybutyric acid & 2 & 1 & $0-3$ \\
\hline Current Smoking & 121 & 81 & $75-87$ \\
\hline Nicotine Dependence (FTND: 6-10 points) & 62 & 41 & $33-50$ \\
\hline Anxiety Disorders & 65 & 43 & 36-51 \\
\hline Current panic disorder & 7 & 5 & $1-8$ \\
\hline Lifetime panic disorder & 25 & 21 & $15-28$ \\
\hline Agoraphobia & 18 & 12 & $7-17$ \\
\hline Social anxiety disorder & 7 & 5 & $1-8$ \\
\hline Generalised anxiety disorder & 3 & 2 & $0-5$ \\
\hline Obsessive compulsive disorder & 11 & 7 & $3-11$ \\
\hline Posttraumatic stress disorder & 39 & 26 & $19-33$ \\
\hline Current psychotic disorder & 3 & 2 & $0-5$ \\
\hline Lifetime psychotic disorder & 8 & 5 & $2-9$ \\
\hline
\end{tabular}




\begin{tabular}{|l|l|l|l|}
\hline $\begin{array}{l}\text { Anorexia nervosa } \\
\text { Bulimia nervosa }\end{array}$ & 4 & 3 & $1-5$ \\
\hline Personality disorder (BPD/ASPD) & $\mathbf{5 3}$ & $\mathbf{3 5}$ & $\mathbf{2 8 - 4 3}$ \\
\hline Antisocial personality disorder & 41 & 27 & $20-38$ \\
Borderline personality disorder & 22 & 15 & $9-21$ \\
\hline Risk of Suicide & & & \\
\hline $\boldsymbol{\bullet}$ None & 70 & 47 & $38-55$ \\
$\boldsymbol{\bullet}$ Low & 63 & 42 & $34-51$ \\
$\boldsymbol{\bullet}$ Medium & 5 & 3 & $1-6$ \\
\hline
\end{tabular}

*one year prevalence rates; $\mathrm{BPD}=$ borderline personality disorder; $\mathrm{APD}=$ antisocial personality disorder

Comorbidities of mental health and substance use disorders are shown in Table 2. Ninety per cent of the people with addiction had at least one other mental disorder. Addiction cooccurred with affective disorders in $n=63(68 \%)$, with anxiety disorders in $n=41(44 \%)$, with personality disorders in $n=44(47 \%)$ and with suicidal ideation in $n=54(58 \%)$. People with different types of addiction, such as alcohol use disorders, illicit drug use disorders and among them the subgroup with opiate addiction had comorbidities with a range of different psychiatric disorders. There was no specific pattern of comorbidities associated with addiction or any of the different types of addiction. 
Table 2: Substance use disorders and their comorbidities in female prisoners. Patterns of comorbidities are shown for subgroups of prisoners with alcohol use, drug use and opiate use disorders.

\begin{tabular}{|c|c|c|c|c|c|c|c|c|}
\hline \multirow[b]{2}{*}{ Mental disorder } & \multicolumn{2}{|c|}{\begin{tabular}{|l|} 
Substance use \\
disorders (without \\
nicotine) $\mathrm{N}=93$
\end{tabular}} & \multicolumn{2}{|c|}{$\begin{array}{l}\text { Alcohol use disorders } \\
\mathbf{N}=\mathbf{5 7}\end{array}$} & \multicolumn{2}{|c|}{$\begin{array}{l}\text { Illicit drug use } \\
\text { disorders } N=76\end{array}$} & \multicolumn{2}{|c|}{$\begin{array}{l}\text { Opiate use disorders } \\
\mathrm{N}=53\end{array}$} \\
\hline & $\mathbf{N}$ & $\%$ & $\mathbf{N}$ & $\%$ & $\mathbf{N}$ & $\%$ & $\mathbf{N}$ & $\%$ \\
\hline$\geq 2$ disorder & 84 & 90 & 45 & 92 & 71 & 93 & 49 & 93 \\
\hline Lifetime affective disorders & 63 & 68 & 34 & 69 & 52 & 68 & 34 & 64 \\
\hline Major depression & 3 & 3 & 0 & & 3 & 4 & 2 & 4 \\
\hline Recurrent major depression & 9 & 10 & 5 & 10 & 8 & 11 & 7 & 13 \\
\hline Previous Major Depression & 10 & 11 & 4 & 8 & 9 & 12 & 8 & 15 \\
\hline Previous recurrent major depression & 15 & 16 & 7 & 14 & 13 & 17 & 9 & 17 \\
\hline Mania & 0 & & 0 & & 0 & & 0 & \\
\hline Previous mania & 2 & 2 & 1 & 2 & 2 & 3 & 2 & 4 \\
\hline Bipolar I disorder & 11 & 12 & 8 & 16 & 8 & 11 & 3 & 6 \\
\hline Previous bipolar I disorder & 9 & 10 & 6 & 12 & 7 & 9 & 2 & 4 \\
\hline Bipolar II disorder & 1 & 1 & 1 & 2 & 0 & & 0 & \\
\hline Previous bipolar II disorder & 3 & 3 & 2 & 4 & 2 & 3 & 1 & 2 \\
\hline Current affective disorder with psychotic features & 1 & 1 & 1 & 2 & 0 & & 0 & \\
\hline Lifetime affective disorders with psychotic symptoms & 6 & 6 & 4 & 8 & 4 & 5 & 3 & 6 \\
\hline Alcohol abuse/dependence & 49 & 53 & & & 32 & 42 & 19 & 36 \\
\hline Alcohol abuse & 18 & 19 & 18 & 37 & 12 & 16 & 5 & 9 \\
\hline Alcohol dependence & 31 & 33 & 31 & 63 & 20 & 26 & 14 & 26 \\
\hline Illicit drug abuse/dependence & 76 & 82 & 32 & 65 & & & & \\
\hline
\end{tabular}




\begin{tabular}{|c|c|c|c|c|c|c|c|c|}
\hline$\circ \quad$ Opiate substitution & $\mid 19$ & 20 & 9 & 18 & $\mid 19$ & 25 & 19 & 36 \\
\hline - Marihuana & 28 & 30 & 14 & 29 & 26 & 34 & 17 & 32 \\
\hline - Cocaine & 25 & 27 & 12 & 24 & 25 & 33 & 20 & 38 \\
\hline - Amphetamines & 14 & 15 & 9 & 18 & 14 & 18 & 8 & 15 \\
\hline - Hallucinogenics & 3 & 3 & 2 & 4 & 3 & 4 & 0 & \\
\hline - Gamma-Hydroxybutyric acid & 2 & 2 & 2 & 4 & 2 & 3 & 1 & 2 \\
\hline Current Smoking & 86 & 92 & 45 & 92 & 70 & 92 & 53 & 100 \\
\hline Nicotine Dependence (FTND: 6-10 points) & 46 & 49 & 27 & 55 & 35 & 46 & 27 & 51 \\
\hline Anxiety Disorders & 41 & 44 & 23 & 47 & 32 & 42 & 21 & 40 \\
\hline Current panic disorder & 5 & 5 & 3 & 6 & 4 & 5 & 3 & 6 \\
\hline Lifetime panic disorder & 19 & 20 & 7 & 14 & 12 & 16 & 10 & 19 \\
\hline Agoraphobia & 12 & 13 & 9 & 18 & 6 & 8 & 5 & 9 \\
\hline Social anxiety disorder & 6 & 7 & 5 & 10 & 4 & 5 & 2 & 4 \\
\hline Generalised anxiety disorder & 2 & 2 & 2 & 4 & 1 & 1 & 1 & 2 \\
\hline Obsessive compulsive disorder & 7 & 8 & 5 & 10 & 6 & 8 & 4 & 8 \\
\hline Posttraumatic stress disorder & 26 & 28 & 15 & 31 & 23 & 30 & 15 & 28 \\
\hline Current psychotic disorder & $\mathbf{0}$ & & $\mathbf{0}$ & & $\mathbf{0}$ & & $\mathbf{0}$ & \\
\hline Lifetime psychotic disorder & 7 & 8 & 5 & 10 & 6 & 8 & 5 & 9 \\
\hline $\begin{array}{l}\text { Anorexia nervosa } \\
\text { Bulimia nervosa }\end{array}$ & $\begin{array}{l}3 \\
0\end{array}$ & 3 & $\begin{array}{l}2 \\
0\end{array}$ & 4 & $\begin{array}{l}2 \\
0\end{array}$ & 3 & $\begin{array}{l}2 \\
0\end{array}$ & 4 \\
\hline Personality disorder (BPD/ASPD) & 44 & 47 & 18 & 37 & 37 & 49 & 27 & 51 \\
\hline Antisocial personality disorder & 35 & 38 & 18 & 37 & 29 & 38 & 24 & 45 \\
\hline Borderline personality disorder & 16 & 17 & 11 & 24 & 13 & 17 & 7 & 13 \\
\hline \multicolumn{9}{|l|}{ Risk of Suicide } \\
\hline - None & 39 & 42 & 21 & 43 & 33 & 43 & 24 & 45 \\
\hline - Low & 42 & 45 & 24 & 49 & 32 & 42 & 22 & 42 \\
\hline - $\quad$ Medium & 2 & 2 & 1 & 2 & 1 & 1 & 1 & 2 \\
\hline - High & 10 & 11 & 3 & 6 & 10 & 13 & 6 & 11 \\
\hline
\end{tabular}




\section{Discussion}

\section{Main results}

About two thirds of the consecutively admitted female prisoners had substance use disorders, mainly associated with opiates. Of the prisoners with addiction, $90 \%$ had at least one other mental disorder. Different types of addiction frequently co-occurred with affective, personality and anxiety disorders.

\section{Strengths and limitations}

This is the first study that systematically explores the comorbidity of substance use disorders and mental disorders in female prisoners at admission to the penal justice system. The study recruited consecutively admitted women so that the sample included newly received female prisoners regardless of their length or type of verdict. Independent researchers established diagnoses using standardised instruments.

The study also has several limitations. Firstly, the recruitment was carried out in one site responsible for all admissions of female prisoners in one German metropolitan area and it remains unclear as to what degree the findings can be generalised to other regions in Germany or internationally to other legal, social and cultural contexts. Secondly, the sample did not include non-German speaking prisoners, and the prevalence of both addiction disorders and other comorbid mental disorders may be different in migrants.

\section{Comparison against the literature}

The prevalence rates of mental health and substance use disorders found in our study are much higher than in the female general population in Germany [34]. This is inline with most previous prison research [9]. Whereas the rates of serious mental illnesses were within the expected range from previous prison studies [17], the rate of alcohol addiction was even higher than 
expected from the literature [9].

Most previous prison mental health studies used sampling designs including all existing inmates. Those studies recruited largely longer-term prisoners as compared to studies sampling from all admissions to a system. In samples of all existing prisoners at least part of the sample is under forced abstinence when assessment takes place. They may therefore be less meaningful to assess addictions and comorbidities. The most comparable study to ours reported prevalence rates of female prisoners in the US [35]. It used the same diagnostic instrument and same sampling strategy [35]. Surprisingly similar rates were found for current major depression (14\% US vs. $13 \%$ present), PTSD (23\% US vs. $26 \%$ present), substance use disorders (68\% US vs. $62 \%$ present) and APD (27\% US vs. $27 \%$ present), whereas even higher rates were reported for current bipolar disorder ( $25 \%$ US vs. $10 \%$ present). Given that our study showed very similar prevalence rates of mental health and substance use disorders in the total sample compared to the study conducted in the US, the comorbidities reported in this study may be generalizable to wider contexts including the US. Female prisoners with substance use disorders and several subgroups with specific addictions (to alcohol, drugs and opiates) very commonly also had affective, personality and anxiety disorders without any specific patterns of comorbidities. The rates of comorbid anxiety disorders or depression in female prisoners with opiate addiction were higher than the rates of those comorbidities reported for people with opiate addiction in community addiction treatments [36]. The findings indicate that the development of adequate interventions for prisoners has to consider addiction commonly cooccurring with a range of comorbidities. Any pure addiction focus or focusing on a specific dual disorder may not be sufficient to plan the provision of adequate services.

\section{Implications for research, politics and health service development}

Prevalence rates of mental health and substance use disorders of prison populations could be more similar across different international contexts than previously thought, if studies using the 
same structured interview and the same sampling strategy were compared. Effective interventions need likely to be non-specific with respect to the disorder, generic, robust and flexible. They need to contain elements to sustain abstinence beyond imprisonment but also need to allow for comorbidities of a range of other mental health conditions. Interventions not focussing on pathologies or deficits at all, such as resource-oriented therapies could be a promising option for future developments [37].

\section{References}

$1 \quad$ Walmsley R: World Female Imprisonment List, Second Edition. http://www.prisonstudies.org/sites/prisonstudies.org/files/resources/downloads/wfil_2nd_editio n.pdf, (accessed 28.10.2014).

2 van den Bergh BJ, Gatherer A, Moller LF: Women's health in prison: urgent need for improvement in gender equity and social justice. Bull World Health Organ 2009;87:406. 3 Jordan BK, Schlenger WE, Fairbank JA, Caddell JM: Prevalence of psychiatric disorders among incarcerated women. II. Convicted felons entering prison. Arch Gen Psychiatry 1996;53:513-519.

4 von Schönfeld CE, Schneider F, Schroder T, Widmann B, Botthof U, Driessen M: Prävalenz psychischer Störungen, Psychopathologie und Behandlungsbedarf bei weiblichen und männlichen Gefangenen. Der Nervenarzt 2006;77:830-841.

5 Butler T, Allnutt S, Cain D, Owens D, Muller C: Mental disorder in the New South Wales prisoner population. Aust N Z J Psychiatry 2005;39:407-413.

6 Binswanger IA, Merrill JO, Krueger PM, White MC, Booth RE, Elmore JG: Gender differences in chronic medical, psychiatric, and substance-dependence disorders among jail inmates. Am J Public Health 2010;100:476-482.

$7 \quad$ Fazel S, Baillargeon J: The health of prisoners. Lancet 2011;377:956-965. 
8 Steadman HJ, Osher FC, Robbins PC, Case B, Samuels S: Prevalence of serious mental illness among jail inmates. Psychiatr Serv 2009;60:761-765.

9 Fazel S, Bains P, Doll H: Substance abuse and dependence in prisoners: a systematic review. Addiction 2006;101:181-191.

10 Daniel AE, Robins AJ, Reid JC, Wilfley DE: Lifetime and six-month prevalence of psychiatric disorders among sentenced female offenders. Bull Am Acad Psychiatry Law 1988;16:333-342.

11 Johnson H: Drug use by incarcerated women offenders. Drug and alcohol review 2006;25:433-437.

12 Wright B, Duffy D, Curtin K, Linehan S, Monks S, Kennedy HG: Psychiatric morbidity among women prisoners newly committed and amongst remanded and sentenced women amongst the Irish prison system. Ir J Psych Med 2006;23:47-53.

13 Maden A, Swinton M, Gunn J: Women in prison and use of illicit drugs before arrest. BMJ 1990;301:1133.

14 Brooke D, Taylor C, Gunn J, Maden A: Substance misusers remanded to prison--a treatment opportunity? Addiction 1998;93:1851-1856.

15 van Emmerik-van Oortmerssen K, van de Glind G, Koeter MW, Allsop S, Auriacombe M, Barta C, Bu ET, Burren Y, Carpentier PJ, Carruthers S, Casas M, Demetrovics Z, Dom G, Faraone SV, Fatseas M, Franck J, Johnson B, Kapitany-Foveny M, Kaye S, Konstenius M, Levin FR, Moggi F, Moller M, Ramos-Quiroga JA, Schillinger A, Skutle A, Verspreet S, van den Brink W, Schoevers RA: Psychiatric comorbidity in treatment-seeking substance use disorder patients with and without attention deficit hyperactivity disorder: results of the IASP study. Addiction 2014;109:262-272.

16 Compton WM, Thomas YF, Stinson FS, Grant BF: Prevalence, correlates, disability, and comorbidity of DSM-IV drug abuse and dependence in the United States: results from the national epidemiologic survey on alcohol and related conditions. Arch Gen Psychiatry 
2007;64:566-576.

17 Fazel S, Seewald K: Severe mental illness in 33588 prisoners worldwide: systematic review and meta-regression analysis. Br J Psychiatry 2012;200:364-373.

18 Mundt AP, Alvarado R, Fritsch R, Poblete C, Villagra C, Kastner S, Priebe S:

Prevalence rates of mental disorders in chilean prisons. PloS one 2013;8:e69109.

19 Clarke JG, Stein LA, Martin RA, Martin SA, Parker D, Lopes CE, McGovern AR, Simon R, Roberts M, Friedman P, Bock B: Forced smoking abstinence: not enough for smoking cessation. JAMA internal medicine 2013;173:789-794.

20 von Schönfeld CE, Schneider F, Schroder T, Widmann B, Botthof U, Driessen M:

Prevalence of psychiatric disorders, psychopathology, and the need for treatment in female and male prisoners. Der Nervenarzt 2006;77:830-841.

21 Dudeck M, Kopp D, Kuwert P, Drenkhahn K, Orlob S, Luth HJ, Freyberger HJ, Spitzer

C: Prevalence of psychiatric disorders in prisoners with a short imprisonment: results from a prison in north Germany. Psychiatr Prax 2009;36:219-224.

22 Driessen M, Schroeder T, Widmann B, von Schonfeld CE, Schneider F: Childhood trauma, psychiatric disorders, and criminal behavior in prisoners in Germany: a comparative study in incarcerated women and men. J Clin Psychiatry 2006;67:1486-1492.

23 UNESCO Institute for Statistics: International Standard Classification of Education ISCED 2011. http://www.uis.unesco.org/Education/Documents/isced-2011-en.pdf, (19 Aug).

24 Mundt A, Kliewe T, Yayla S, Ignatyev Y, Busch M, Heimann H, Heinz A, Rapp M, Schouler-Ocak M, Strohle A, Aichberger M: Social characteristics of psychological distress in disadvantaged areas of Berlin. Int J Soc Psychiatry 2014;60:75-82.

25 Schenk L, Bau AM, Borde T, Butler J, Lampert T, Neuhauser H, Razum O, Weilandt C: A basic set of indicators for mapping migrant status. Recommendations for epidemiological practice. Bundesgesundheitsblatt, Gesundheitsforschung, Gesundheitsschutz 2006;49:853-860. 26 Sheehan DV, Lecrubier Y, Sheehan KH, Amorim P, Janavs J, Weiller E, Hergueta T, 
Baker R, Dunbar GC: The Mini-International Neuropsychiatric Interview (M.I.N.I.): the development and validation of a structured diagnostic psychiatric interview for DSM-IV and ICD-10. J Clin Psychiatry 1998;59 Suppl 20:22-33;quiz 34-57.

27 Sheehan DV, Lecrubier Y, Sheehan KH, Janavs J, Weiller E, Keskiner A, Schinka J, Knapp E, Sheehan MF, Dunbar GC: The validity of the Mini International Neuropsychiatric Interview (MINI) according to the SCID-P and its reliability. Eur Psychiatry 1997;12:232-241. 28 Fydrich T, Renneberg B, Schmitz B, Wittchen HU: SKID-II. Strukturiertes Klinisches Interview für DSM-IV. Achse II: Persönlichkeitsstörungen. Göttingen, Hogrefe, 1997. 29 Arntz A, van Beijsterveldt B, Hoekstra R, Hofman A, Eussen M, Sallaerts S: The interrater reliability of a Dutch version of the Structured Clinical Interview for DSM-III-R Personality Disorders. Acta Psychiatr Scand 1992;85:394-400.

30 First MB, Spitzer RL, Gibbon M, Williams JBW, Davies M, Borus J, Howes MJ, Kane J, Pope HG, Rounsaville B: The Structured Clinical Interview for Dsm-Iii-R PersonalityDisorders (Scid-Ii) .2. Multisite Test-Retest Reliability Study. J Personal Disord 1995;9:92104.

31 Heatherton TF, Kozlowski LT, Frecker RC, Fagerström KO: The Fagerström Test for Nicotine Dependence: a revision of the Fagerström Tolerance Questionnaire. Br J Addict 1991;86:1119-1127.

32 Payne TJ, Smith PO, McCracken LM, McSherry WC, Antony MM: Assessing Nicotine Dependence - a Comparison of the Fagerstrom Tolerance Questionnaire (FTQ) with the Fagerstrom Test for Nicotine Dependence (FTND) in a Clinical-Sample. Addict Behav 1994;19:307-317.

33 Burling AS, Burling TA: A comparison of self-report measures of nicotine dependence among male drug/alcohol-dependent cigarette smokers. Nicotine Tob Res 2003;5:625-633.

34 Jacobi F, Hofler M, Strehle J, Mack S, Gerschler A, Scholl L, Busch MA, Maske U, Hapke U, Gaebel W, Maier W, Wagner M, Zielasek J, Wittchen HU: Mental disorders in the 
general population : Study on the health of adults in Germany and the additional module mental health (DEGS1-MH). Nervenarzt 2014;85:77-87.

35 Gunter TD, Arndt S, Wenman G, Allen J, Loveless P, Sieleni B, Black DW: Frequency of mental and addictive disorders among 320 men and women entering the Iowa prison system: use of the MINI-Plus. J Am Acad Psychiatry Law 2008;36:27-34.

36 Goldner EM, Lusted A, Roerecke M, Rehm J, Fischer B: Prevalence of Axis-1 psychiatric (with focus on depression and anxiety) disorder and symptomatology among nonmedical prescription opioid users in substance use treatment: systematic review and metaanalyses. Addict Behav 2014;39:520-531.

37 Priebe S, Omer S, Giacco D, Slade M: Resource-oriented therapeutic models in psychiatry: conceptual review. Br J Psychiatry 2014;204:256-261. 